Article

\title{
Radiation-Induced Structural Changes of Miscanthus Biomass
}

\author{
Xiao-Jun Su ${ }^{1,2}{ }^{\text {, Chun-Yan Zhang }}{ }^{1}$, Wen-Jia Li ${ }^{1}$, Feng Wang ${ }^{1}$, Ke-Qin Wang ${ }^{3}$, Yun Liu ${ }^{4,5,6,7, *}$ \\ and Qing-Ming $\mathrm{Li}^{1,2, * \text { (D) }}$ \\ 1 College of Food Science and Technology, Hunan Agricultural University, Changsha 410128, China; \\ suxiaojun5606@163.com (X.-J.S.); zhangchy95@163.com (C.-Y.Z.); liwenjia9301@163.com (W.-J.L.); \\ wanglaofeng@163.com (F.W.) \\ 2 Hunan Engineering Laboratory for Alcohol Fuels from Biomass, Changsha 410128, China \\ 3 Institute of Nuclear Agricultural Science and Space Breeding, Hunan Academy of Agriculture Sciences, \\ Changsha 410125, China; wkq6412@163.com \\ 4 College of Life Science and Technology, Beijing University of Chemical Technology, Beijing 100029, China \\ 5 School of Nuclear Technology and Chemistry \& Biology, Hubei University of Science and Technology, \\ Xianning 437100, China \\ 6 Hubei Key Laboratory of Radiation Chemistry and Functional Materials, Hubei University of Science and \\ Technology, Xianning 437100, China \\ 7 Hubei Engineering Research Center for Fragrant Plants, Hubei University of Science and Technology, \\ Xianning 437100, China \\ * Correspondence: liuyun@mail.buct.edu.cn (Y.L.); liqmemail@163.com (Q.-M.L.)
}

Received: 14 January 2020; Accepted: 4 February 2020; Published: 7 February 2020

\begin{abstract}
Efficient pretreatment is a prerequisite for lignocellulosic biomass biorefinery due to the structure of lignocellulose. This study is a first-time investigation into the structural changes of Miscanthus biomass treated with ${ }^{60} \mathrm{Co} \gamma$-ray irradiation in different doses up to $1200 \mathrm{kGy}$. The structural properties of the treated sample have been systematically characterized by FTIR, thermogravimetric analysis (TGA), XRD, gel permeation chromatography (GPC), a laser particle size analyzer, SEM, an atomic force microscope (AFM), and NMR. The results show that irradiation treatment can partially destroy the intra- or inter-molecular hydrogen bonds of biomass. Irradiation treatment can also reduce particle size, narrow the distribution range, as well as increase the specific surface area of biomasses. Noticeably, the TGA stability of the treated biomass decreases with increasing absorbed doses. To respond to these structural changes, the treated biomass can be easily hydrolyzed by cellulases with a high yield of reducing sugars (557.58 $\mathrm{mg} / \mathrm{g}$ biomass), much higher than that of the untreated sample. We conclude that irradiation treatment can damage biomass structure, a promising strategy for biomass biorefinery in the future.
\end{abstract}

Keywords: Miscanthus biomass; irradiation pretreatment; recalcitrant; structural properties; enzymatic hydrolysis

\section{Introduction}

As a $\mathrm{C}_{4}$ perennial grass, Miscanthus is an important potential energy crop in China and Europe. It is characterized by higher adaptability, bio-production, and fiber content, as well as lower ash content and input requirements in comparison to conventional crops [1,2]. The chemical composition of Miscanthus includes cellulose (370-501 g/kg dry solids), hemicellulose (283-354 g/kg dry solids), and lignin (68.7-127.6 g/kg dry solids) [3]. Biofuels and biochemicals from Miscanthus have been comprehensively studied in the past few years. However, the recalcitrant structure of biomass has become one of the main factors restricting biofuel production [1,4]. Cellulose and hemicellulose 
constitute the whole biomass and are firmly linked with lignin molecules through covalent and hydrogenic bonds, which make the biomass structure extremely strong and difficult to pretreat $[5,6]$. To enhance cellulose hydrolysis, the method of biomass pretreatment should efficiently damage the recalcitrant biomass structure [7-9]. In recent years, many researchers have reported a number of excellent pretreatment strategies, including milling, alkali, acid, hydrothermal and ammonia explosion methods, as well as biological degradation [1,3,9-12].

Recently, more efforts have focused on irradiation pretreatment of biomass using mild temperatures, no water washing, and minimal use of undesirable inhibitory products [13]. Moreover, irradiation pretreatment can significantly damage the recalcitrant structure of lignocellulosic biomass, especially degrading cellulose structure, which facilitates the downstream enzymatic saccharification [14]. In our previous studies, the effect of irradiation pretreatment on the structure of microcrystal cellulose as well as hemicellulose was intensively investigated [15,16], and we demonstrated that irradiation pretreatment followed by enzymatic hydrolysis can result in high sugar yields [17]. Therefore, irradiation pretreatment may be one of the most promising methods to overcome this recalcitrance.

To date, little information has been reported on the degradation mechanism of real biomass treated by irradiation. In this work, irradiation pretreatment was employed to degrade the structure of Miscanthus to improve its downstream enzymatic hydrolysis. The effect of different absorbed doses up to $1200 \mathrm{kGy}$ on recalcitrant structures is illustrated to better understand the degradation mechanism of irradiation treatment.

\section{Materials and Methods}

\subsection{Materials}

Miscanthus floridulus was gathered from a local experimental base in Hunan Agricultural University, China. After it was dried in an oven at $60^{\circ} \mathrm{C}$ for $8 \mathrm{~h}$, the samples were ground and sieved through 40 mesh(the particle size of sample is approx. $425 \mu \mathrm{m}$ ). The feedstock was stored at room temperature for the following experiments.

\section{2. ${ }^{60} \mathrm{Co} \gamma$-Ray Irradiation Pretreatment of Miscanthus}

The procedures of irradiation treatment and enzymatic hydrolysis were conducted according to the method reported by Liu et al. [14]. Briefly, the irradiation treatment experiments were carried out on a ${ }^{60} \mathrm{Co} \gamma$-ray irradiation device at $1.85 \times 10^{16} \mathrm{~Bq}$ in the Hunan Irradiation Center (Liuyang City, China). Approximately $200 \mathrm{~g}$ of grounded dry Miscanthus biomass was put in a glass bottle, and then irradiated at a ${ }^{60} \mathrm{Co}-\gamma$ radiation source intensity of $9.99 \times 10^{15} \mathrm{~Bq}$ at $2.0 \mathrm{kGy} \mathrm{h}^{-1}$ dose rate. The specific levels of absorbed doses were fixed at 0 (untreated as blank control), 400, 600, 800, 1000, and $1200 \mathrm{kGy}$.

\subsection{Chemical Compositions Analyses}

The chemical compositions of Miscanthus, including the content of moisture, cellulose, lignin, and reducing sugar before and after irradiation treatment were determined using the analytical methods provided in the GB/T 2677 standard. The content of hemicellulose was calculated by subtracting cellulose from holocellulose [18]. Each experimental result was repeated in triplicate.

\subsection{Structural Properties of the Irradiated Miscanthus}

\subsubsection{Gel Permeation Chromatography (GPC)}

The GPC method was employed to determine the molecular weight (MW) distribution of irradiated Miscanthus, and the detailed procedure of GPC was described in a previous study [16]. 


\subsubsection{X-Ray Diffraction Analysis (XRD)}

The crystalline phase of irradiated Miscanthus cellulose was demonstrated by a D/max 2500 diffractometer (Rigaku Corporation, Tokyo, Japan). The conditions were: acceleration voltage $40 \mathrm{~kW}$ and current $30 \mathrm{~mA}$. The $\mathrm{Cu}-\mathrm{K} \alpha$ wavelength was $1.54 \AA$, grade range $2 \theta$ ranged from $10^{\circ}$ to $40^{\circ}$ with the step size of $0.002^{\circ}$. The crystallinity index (CrI) of cellulose was calculated using Equation (1) [18]

$$
\operatorname{CrI}(\%)=\frac{I_{002}-I_{a m}}{I_{002}} \times 100
$$

where $\mathrm{CrI}$ is the crystallinity index, $I_{002}$ is for the highest peak intensity at $2 \theta=22.6^{\circ}$, and $I_{\mathrm{am}}$ is the intensity diffraction for amorphous cellulose at $2 \theta=16.0^{\circ}$.

\subsubsection{Solid State ${ }^{1} \mathrm{H}$ and ${ }^{13} \mathrm{C}$ nuclear magnetic resonance (NMR)}

${ }^{1} \mathrm{H}$ and ${ }^{13} \mathrm{C}$ NMR measurements were conducted on a Bruker AVANCE III-HD 600 spectrometer (Bruker, Priyanka City, Germany). Their resonance frequencies were 600.1 and $150.9 \mathrm{MHz}$, respectively. ${ }^{1} \mathrm{H}$ and ${ }^{13} \mathrm{C}$ NMR spectra were both recorded using a $4 \mathrm{~mm}$ magic angle spinning (MAS) probe equipped with a spinning rate of $14 \mathrm{kHz}$. Other conditions of the ${ }^{1} \mathrm{H}$ NMR spectra were a $\pi / 2$ pulse length of $2.57 \mu \mathrm{s}$ and a recycle delay of $5 \mathrm{~s}$. Other conditions of ${ }^{13} \mathrm{C}$ NMR spectra were a contact time of $2 \mathrm{~ms}$ and a recycle delay of $5 \mathrm{~s}$.

\subsubsection{Fourier Transform Infrared spectroscopy (FTIR)}

FTIR measurements of Miscanthus samples were carried out on a Prestige-21 FTIR instrument (Shimadzu, Japan). All spectra were recorded in the range of 4000 to $400 \mathrm{~cm}^{-1}$ with an accumulation of 128 scans at $4 \mathrm{~cm}^{-1}$ resolution. Each sample was in conjunction with potassium bromide (KBr) powder and pressed inside a hydraulic press for spectroscopic analytical sample preparation.

\subsubsection{Particle size distribution and specific surface Area (SSA)}

SSA measurement was performed on a laser particle size analyzer (Mastersizer 2000, Malvern, Worcestershire, U.K.). The sample was uniformly dispersed in sodium hexametaphosphate solution, and then loaded into the analyzer for measurement.

\subsubsection{Scanning electron microscope (SEM)}

The morphology of Miscanthus was observed by a JSM-6360LV SEM (Japan Electron Optics Laboratory Co., Ltd., Tokyo, Japan). The samples were first sputter-coated with gold prior to observation by SEM [19].

\subsubsection{Atomic force microscope (AFM)}

The dimension morphology of Miscanthus biomass after irradiation treatment was imaged using AFM (Bruker, Priyanka City, Germany) through ScanAsyst mode with a scanning frequency of $1.49 \mathrm{~Hz}$. All images of height, amplitude and phase were simultaneously obtained in tapping mode with a MPP-11100 etched silicon probe, of which the nominal frequency and nominal spring constant were set at $300 \mathrm{kHz}$ and $40 \mathrm{~N} / \mathrm{m}$, respectively [20].

\subsubsection{Thermogravimetric snalysis (TGA)}

TGA thermal stability of the Miscanthus biomass was determined on a TGA Q50 analyzer (Waters Co., Milford, MA, USA). The $\mathrm{N}_{2}$ with a flow rate of $50 \mathrm{~mL} / \mathrm{min}$ was used as the carrier gas. The temperature ranged from room temperature to $900{ }^{\circ} \mathrm{C}$ with a heating rate of $30^{\circ} \mathrm{C} / \mathrm{min}$. 


\subsubsection{Degree of Polymerization $(D P)$}

The DP of the Miscanthus biomass was measured through the viscosity variance using Ubbelohde viscometry at $25 \pm 0.5^{\circ} \mathrm{C}$. An extrapolation method was used to calculate the intrinsic viscosity $\left(\eta_{t}\right)$ of the sample. Therefore, the values of $\eta_{t}$ and $D P$ were calculated according to Equations (2) and (3):

$$
\begin{gathered}
\eta_{t}=\frac{t-t_{0}}{t_{0}} \\
D P=\frac{2000 \times \eta_{T}}{W \times\left(1+0.29 \times \eta_{T}\right)}
\end{gathered}
$$

where $t_{0}$ and $t_{i}$ are the initial and end times ( $\mathrm{min}$ ) for the cupriethylenediamine solution to run through the capillary, respectively, and $W$ is the mass weight $(\mathrm{g})$ of the sample.

\subsection{Enzymatic Hydrolysis of the Irradiated Miscanthus}

The irradiated Miscanthus biomass was used for enzymatic hydrolysis according to the procedure described by Su et al. [17]. After hydrolysis, the reducing sugars were determined by HPLC. The conditions of HPLC were a temperature of $65^{\circ} \mathrm{C}$, and the mobile phase was $5 \mathrm{mM} \mathrm{H}_{2} \mathrm{SO}_{4}$ at a flow rate of $0.6 \mathrm{~mL} / \mathrm{min}[14]$.

\subsection{Statistical Analysis}

The statistical analyses were determined using SPSS 22.0 (IBM, Armonk, NY, USA), and the final data are expressed by average \pm SD.

\section{Results and Discussion}

\subsection{Effect of Irradiation Treatment on Chemical Compositions of Miscanthus Biomass}

The composition changes of Miscanthus biomass after different absorbed doses are presented in Table 1. As shown in Table 1, the main components of Miscanthus are cellulose, hemicellulose, and lignin, and their total content accounts for $89.7 \%$. In comparison with the compositions of giant reed and Chinese silvergrass reported in the literature, Miscanthus has the same contents of holocellulose and lignin as giant reed, and the total content is higher than Chinese silvergrass [18]. After irradiation treatment, the contents of cellulose and hemicellulose of Miscanthus decreased with the increase in absorbed doses up to $1200 \mathrm{kGy}$, and irradiation treatment had little influence on lignin content. That is, the content of lignin before and after irradiation treatment was almost stable. These phenomena were confirmed by other researches $[18,21]$. The structure of destroyed cellulose can improve enzymatic hydrolysis during downstream saccharification [13]. To illustrate why irradiation has a significant effect on cellulose and hemicellulose but little effect on lignin, the biomass structure was comprehensively elucidated by FTIR, TGA, XRD, GPC, a laser particle size analyzer, SEM, AFM, and NMR in this work.

Table 1. Effect of different absorbed doses on the components of Miscanthus.

\begin{tabular}{ccccccc}
\hline Absorbed Dose (kGy) & 0 (Untreated) & $\mathbf{4 0 0}$ & $\mathbf{6 0 0}$ & $\mathbf{8 0 0}$ & $\mathbf{1 0 0 0}$ & $\mathbf{1 2 0 0}$ \\
\hline Cellulose (\%) & 36.60 & 37.20 & 33.90 & 33.10 & 31.00 & 23.00 \\
Hemicellulose (\%) & 31.80 & 17.80 & 11.60 & 10.50 & 7.40 & 4.90 \\
Lignin (\%) & 21.30 & 23.10 & 21.70 & 22.00 & 23.00 & 19.70 \\
Total (\%) & 89.70 & 78.10 & 67.20 & 65.60 & 61.40 & 47.60 \\
\hline
\end{tabular}

\subsection{Effect of Irradiation Treatment on Enzymatic Hydrolysis of Miscanthus}

Table 2 shows the changes in particle size, distribution, and special surface area of Miscanthus biomass after irradiation treatment. As shown in Table 2, the Sauter mean diameter D [3, 2] and the volume average particle diameter $\mathrm{D}[4,3]$ greatly decreased with the increase in absorbed doses. 
For the untreated sample, the values of $\mathrm{D}[3,2]$ and $\mathrm{D}[4,3]$ were 23.808 and $221.005 \mu \mathrm{m}$, respectively, higher than those of irradiated samples. For instance, after irradiation treatment at $1200 \mathrm{kGy}$, the values of $\mathrm{D}[3,2]$ and $\mathrm{D}[4,3]$ were 7.357 and $20.099 \mu \mathrm{m}$, respectively. In addition, the values of $\mathrm{d}(0.1), \mathrm{d}(0.5)$, and $\mathrm{d}(0.9)$ for untreated samples were 18.026, 153.465, and $547.317 \mu \mathrm{m}$, respectively, whereas for the irradiated samples at $1200 \mathrm{kGy}$, these values significantly reduced to 2.772, 18.423, and $39.082 \mu \mathrm{m}$, respectively. Therefore, an absorbed dose-dependent particle size for irradiated biomass was observed in this work. In detail, with the increase in absorbed doses, particle size distribution moved toward small particles. This showed that the irradiation treatment can remarkably affect both the particle sizes and their distribution due to the destruction of the stubborn structure caused by irradiation. As shown in Table 2, the SSA of the untreated Miscanthus was $0.252 \mathrm{~m}^{2} \mathrm{~g}^{-1}$, whereas for irradiated samples, SSA showed an absorbed dose-dependent increase and the maximum value was $0.815 \mathrm{~m}^{2} \mathrm{~g}^{-1}$ at $1200 \mathrm{kGy}$. These results are in good agreement with our previous works [19,21]. We demonstrated that the increase in SSA enhances the accessibility of enzymes to cellulose substrate, resulting in the improvement of cellulose digestibility.

Table 2. Effect of absorbed doses on particle size and SAA of Miscanthus biomass.

\begin{tabular}{ccccccc}
\hline $\begin{array}{c}\text { Absorbed Dose } \\
(\mathbf{k G y})\end{array}$ & $\begin{array}{c}\text { SSA } \\
\left(\mathbf{m}^{\mathbf{2}} \mathbf{g}\right)\end{array}$ & $\begin{array}{c}\mathbf{D}[\mathbf{3}, \mathbf{2}] \\
(\boldsymbol{\mu \mathbf { m }})\end{array}$ & $\begin{array}{c}\mathbf{D}[\mathbf{4}, \mathbf{3}] \\
(\boldsymbol{\mu \mathbf { m } )}\end{array}$ & $\begin{array}{c}\mathbf{d} \mathbf{( 0 . 1 )} \\
(\boldsymbol{\mu \mathbf { m }})\end{array}$ & $\begin{array}{c}\mathbf{d}(\mathbf{0 . 5}) \\
(\boldsymbol{\mu m})\end{array}$ & $\begin{array}{c}\mathbf{d}(\mathbf{0 . 9}) \\
(\boldsymbol{\mu m})\end{array}$ \\
\hline 0 (Untreated) & 0.252 & 23.808 & 221.005 & 18.026 & 153.465 & 547.317 \\
400 & 0.256 & 23.432 & 203.056 & 14.963 & 131.620 & 496.540 \\
600 & 0.315 & 19.053 & 169.749 & 4.397 & 107.316 & 462.257 \\
800 & 0.319 & 18.806 & 169.307 & 4.641 & 105.537 & 461.163 \\
1000 & 0.642 & 9.343 & 33.060 & 2.924 & 21.181 & 90.421 \\
1200 & 0.815 & 7.357 & 20.099 & 2.772 & 18.423 & 39.082 \\
\hline
\end{tabular}

Note: SSA, specific surface area; D [3, 2], Sauter mean diameter; D [4, 3], the volume mean particle diameter; $\mathrm{d}(0.5)$, median diameter; $\mathrm{d}(0.1), 10 \%$ diameter; $\mathrm{d}(0.9), 90 \%$ diameter.

To further confirm the above-mentioned hypothesis, the irradiated biomass underwent enzymatic hydrolysis to reduce sugar production, and the results are shown in Figure 1. In comparison with the untreated Miscanthus sample, the irradiated sample at over $600 \mathrm{kGy}$ had a higher level of methylene blue adsorption $(596.99 \mu \mathrm{g} / \mathrm{g})$ and a higher reduced sugar yield $(557.58 \mathrm{mg} / \mathrm{g})$. The methylene blue adsorption, a factor of enzyme accessibility to the substrate, slowly increased from 555.18 to $596.99 \mu \mathrm{g} / \mathrm{g}$ in the tested absorbed doses. It increased sugar reduction from 118.27 to $557.58 \mathrm{mg} / \mathrm{g}$. A reasonable explanation is that the accessibility of enzymes increased after the biomass was treated by irradiation, indicating irradiation pretreatment is an effective method to improve the efficiency of enzymatic hydrolysis of a biomass. This phenomenon is in good agreement with that reported by Beardmore et al. [22], who demonstrated that SSA improvement of sulfite pulp increases the efficiency of enzymatic hydrolysis.

\subsection{Influence of Irradiation Treatment on Structural Properties of Miscanthus Biomass}

\subsubsection{DP, CrI, and Molecular Weight Distribution}

The effect of irradiation treatment on molecular weight distribution, $D P$, and CrI of Miscanthus biomass was investigated, and the results are shown in Table 3 . When the biomass was irradiated from 0 to $1200 \mathrm{kGy}$, the $D P$ values decreased from 366,225 to 11,354 , indicating that irradiation treatment can destroy the biomass structure. Moreover, the values for Mw(the weight average molecular mass) and $\mathrm{Mn}$ (the number average molecular mass) decreased with the increase in absorbed doses. Briefly, the $\mathrm{Mw}$ and $\mathrm{Mn}$ values of the untreated samples (0 kGy) were 542,342 and 45,544 Da, respectively, whereas for the irradiated samples at $1200 \mathrm{kGy}$, the values of Mw and Mn decreased to 150,821 and $30,237 \mathrm{Da}$, respectively. In comparison with the untreated sample, the value of $\mathrm{Mw} / \mathrm{Mn}$ decreased after irradiation treatment. However, the value of $\mathrm{Mw} / \mathrm{Mn}$ showed no absorbed dose dependence due to 
the similar decrease variance in Mw and Mn values. We found that the Miscanthus macromolecular structure was degraded after irradiation treatment [23]. These structural changes in biomass are helpful for enzymatic hydrolysis [24]. Table 3 shows that the $\mathrm{CrI}$ values of irradiated samples showed a dose-dependent decreasing tendency, which also improved the enzymatic hydrolysis efficiency. The change in $\mathrm{CrI}$ values demonstrated that irradiation treatment may damage the crystalline structure of cellulose, which was confirmed by TGA analysis in the following experiment.

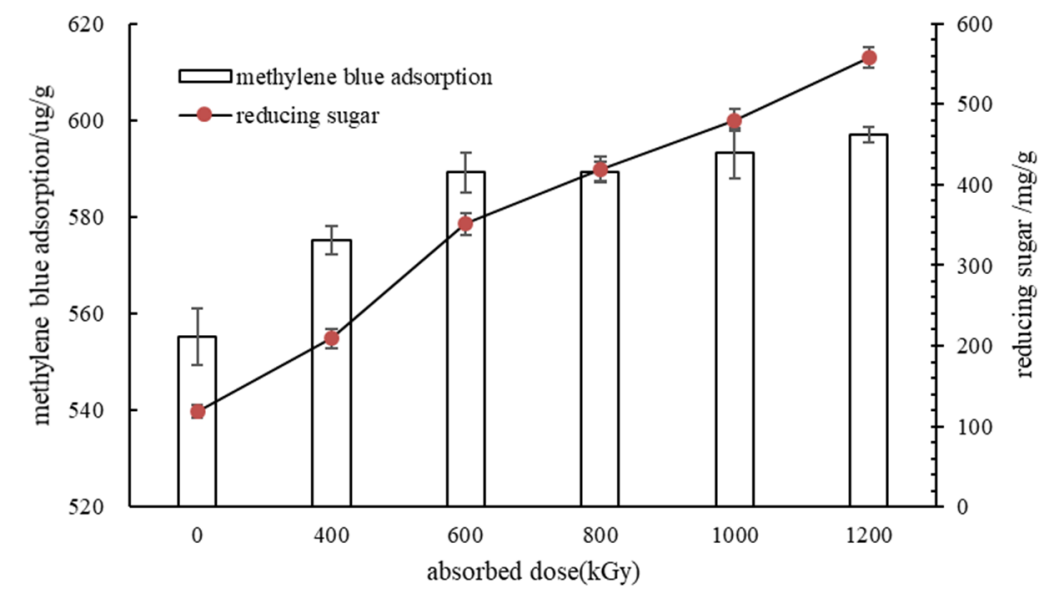

Figure 1. Effect of absorbed dose on reducing sugars yield and methylene blue adsorption.

Table 3. Influence of absorbed doses on molecular weight distribution, $D P$, and $C r I$ of Miscanthus biomass.

\begin{tabular}{ccccccc}
\hline Dose/kGy & $\mathbf{0}$ & $\mathbf{4 0 0}$ & $\mathbf{6 0 0}$ & $\mathbf{8 0 0}$ & $\mathbf{1 0 0 0}$ & $\mathbf{1 2 0 0}$ \\
\hline $\mathrm{Mw}(\mathrm{Da})$ & 542,342 & 228,791 & 168,982 & 160,859 & 151,213 & 150,821 \\
$\mathrm{Mn}(\mathrm{Da})$ & 45,544 & 37,981 & 36,273 & 34,793 & 33,565 & 30,237 \\
$\mathrm{Mw} / \mathrm{Mn}$ & 14.952 & 5.024 & 4.449 & 4.623 & 4.505 & 4.988 \\
$D P$ & 366,225 & 44,230 & 30,947 & 20,569 & 18,200 & 11,354 \\
CrI (\%) & 37.86 & 33.26 & 28.92 & 29.03 & 30.02 & 28.43 \\
\hline
\end{tabular}

Note: $\mathrm{Mw}$, the weight average molecular mass; $\mathrm{Mn}$, the number average molecular mass; $\mathrm{Mw} / \mathrm{Mn}$, the polydispersity index; $D P$, the degree of polymerization; $C r I$, the crystallinity index.

\subsubsection{TGA Measurement}

The TGA thermal stability of biomass usually has two obvious narrow peaks: one is the degradation peak of hemicellulose, the other is the peak of cellulose. However, the TGA peak of lignin is very broad and partly overlaps hemicellulose and cellulose [25]. The TGA profiles of the irradiated Miscanthus biomass are depicted in Figure 2. There are two peaks $\left(\mathrm{T}_{\max \mathrm{L}}\right.$ and $\left.\mathrm{T}_{\max \mathrm{H}}\right)$ observed from TGA curves at doses of 400, 600, and $800 \mathrm{kGy}$, but only a single peak ( $T_{\max } \mathrm{L}$ ) at 1000 and $1200 \mathrm{kGy}$. The disappearance of the high-temperature peak $\left(\mathrm{T}_{\max H}\right)$ was caused by the side chains cleavage of biomass under the higher absorbed doses. In addition, a small shift in $\mathrm{T}_{\max \mathrm{L}}$ value to a lower temperature (Table 3) occurred when absorbed dose increased up to $1200 \mathrm{kGy}$, indicating the backbone of the biomass was degraded by the irradiation treatment. The phenomenon does not align with the $\mathrm{CrI}$ values of cellulose in Table 3. 


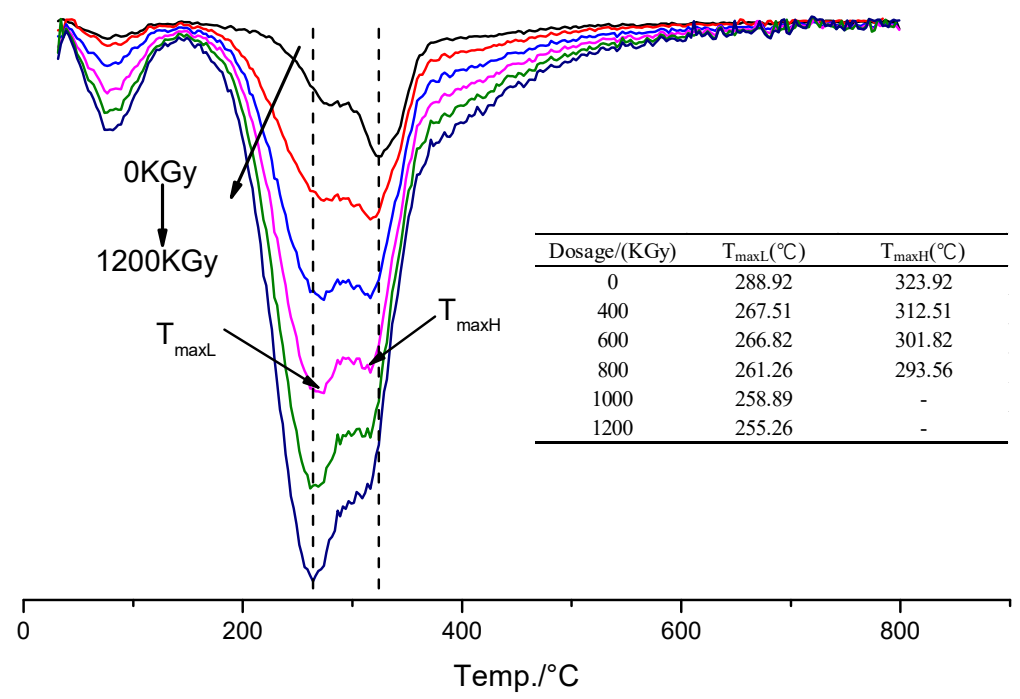

Figure 2. Effect of absorbed doses on the thermal stability profiles of Miscanthus biomass.

\subsubsection{XRD Analysis}

XRD measurement was conducted to assess the crystalline phase of Miscanthus biomass under different absorbed doses. As observed in Figure 3, the $\mathrm{CrI}$ peaks at $\sim 16^{\circ}$ and $22^{\circ}$ lattices remained stable without new lattice generation after irradiation treatment. As described in Table 3, the $\mathrm{CrI}$ values showed an absorbed dose-dependent decrease, indicating the crystalline area of cellulose was destroyed to some extent. The CrI values of irradiated Miscanthus declined slightly from $37.86 \%$ to $28.43 \%$ under the absorbed doses from 0 to $1200 \mathrm{kGy}$ (Table 3). The effect of irradiation treatment on cellulose crystalline phase is dependent on absorbed dosage and the biomass species [16,26]. Huang et al. [26] demonstrated that the crystalline phase cleavage by irradiation treatment is contributed by the enzymatic hydrolysis of biomass.

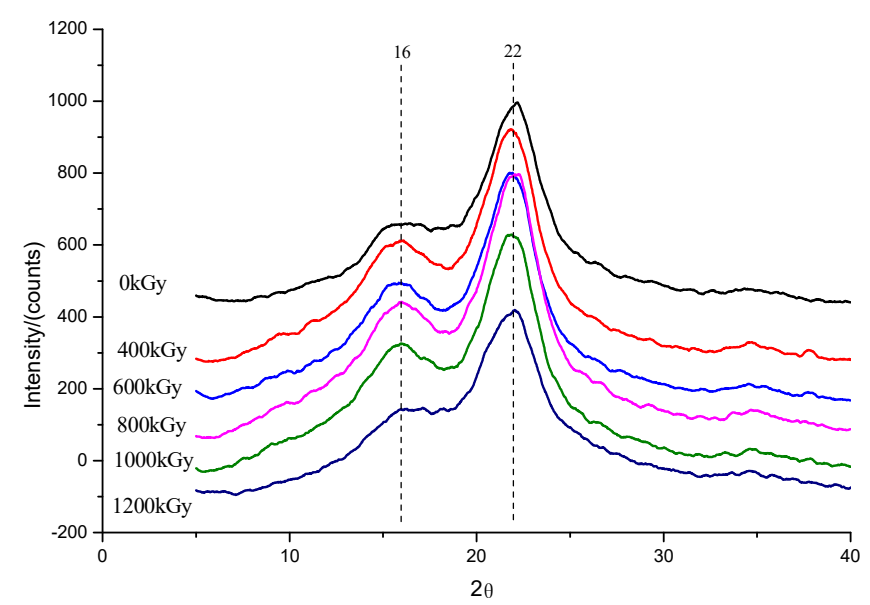

Figure 3. XRD patterns of the Miscanthus biomass irradiated with different doses.

\subsubsection{FTIR Analysis}

The FTIR of Miscanthus biomass after irradiation treatment was investigated, and the spectra are shown in Figure 4. Three characteristic peaks of holocellulose are: $1730 \mathrm{~cm}^{-1}$ is ascribed to $\mathrm{C}=\mathrm{O}$ carbonyl group, $1372 \mathrm{~cm}^{-1}$ is ascribed to $-\mathrm{C}-\mathrm{C}-$, and $1237 \mathrm{~cm}^{-1}$ is ascribed to $\mathrm{C}-\mathrm{O}-$ of acetyl group, as observed in Figure 4. With the increase in absorbed doses, the intensity of the three peaks increased, indicating that the structural damage degree of Miscanthus fibers increases with the increase in the absorbed dose. The changes of the typical peaks of the guaiacyl and syringyl lignin vibration at $1230-1515 \mathrm{~cm}^{-1}$ also showed absorbed dose-dependence. Simultaneously, the peak at $910 \mathrm{~cm}^{-1}$ 
ascribed to the $\mathrm{C}-\mathrm{O}-\mathrm{C}$ group in the epoxide guaiacyl lignin was so small that the change in its height was not significant, which is good agreement with the data of wheat straw treated by irradiation and diluted acid [27].

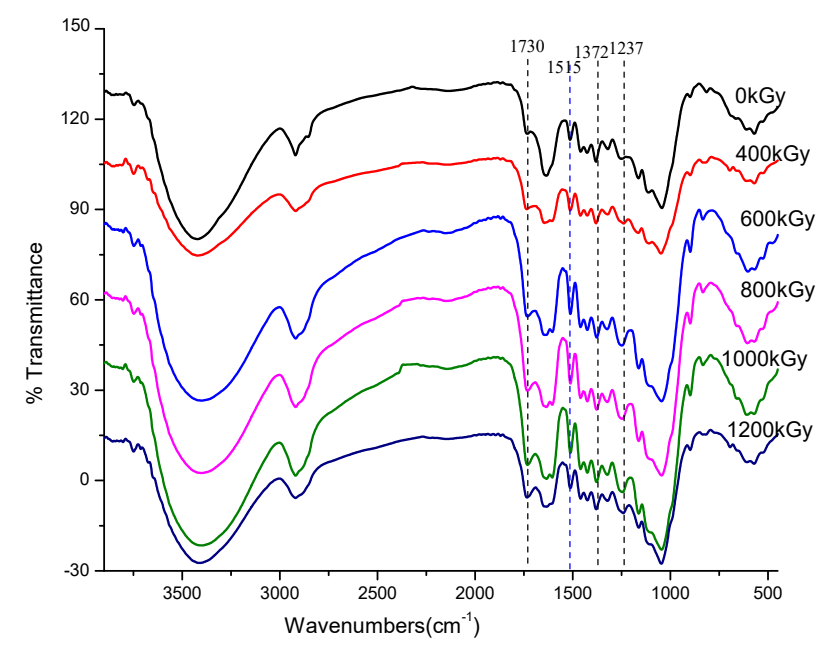

Figure 4. FTIR spectra of Miscanthus irradiated with different absorbed doses.

\subsection{5. ${ }^{1} \mathrm{H}$ and ${ }^{13} \mathrm{C}$ NMR Analysis}

${ }^{1} \mathrm{H}$ and ${ }^{13} \mathrm{C}$ NMR analyses were carried out to evaluate the chemical structural changes of Miscanthus biomass after irradiation treatment, and the data are shown in Figure 5. For the untreated sample $(0 \mathrm{kGy})$, the chemical shift at $5 \mathrm{ppm}$ of ${ }^{1} \mathrm{H}$ NMR profiles was ascribed to the $\mathrm{H}^{+}$proton signal peak of hemicellulose, whereas in the cases of irradiated samples, the ${ }^{1} \mathrm{H}$ proton signal peak was apparently enlarged and shifted to $5.2 \mathrm{ppm}$ with the increase in absorbed doses from 400 to $1200 \mathrm{kGy}$. From the ${ }^{13} \mathrm{C}$ NMR profiles, the peaks intensity of the glucosyl unit at $21.3,74.6$, and $88.7 \mathrm{ppm}$ reduced with the increase in absorbed doses. However, the intensity of the peak at $56.6 \mathrm{ppm}$ increased with the increase in the absorbed dose. These small variations in carbon chemical shifts of irradiated samples may lead to intermolecular $\mathrm{C}-\mathrm{C}$ bond cleavage in backbone structure. In combination with the FTIR, and ${ }^{1} \mathrm{H}$ and ${ }^{13} \mathrm{C}$-NMR profiles, we concluded that inter-molecular hydrogen bonds and carbon-carbon bond cleavage of biomass are caused by high absorbed doses $[13,19]$.
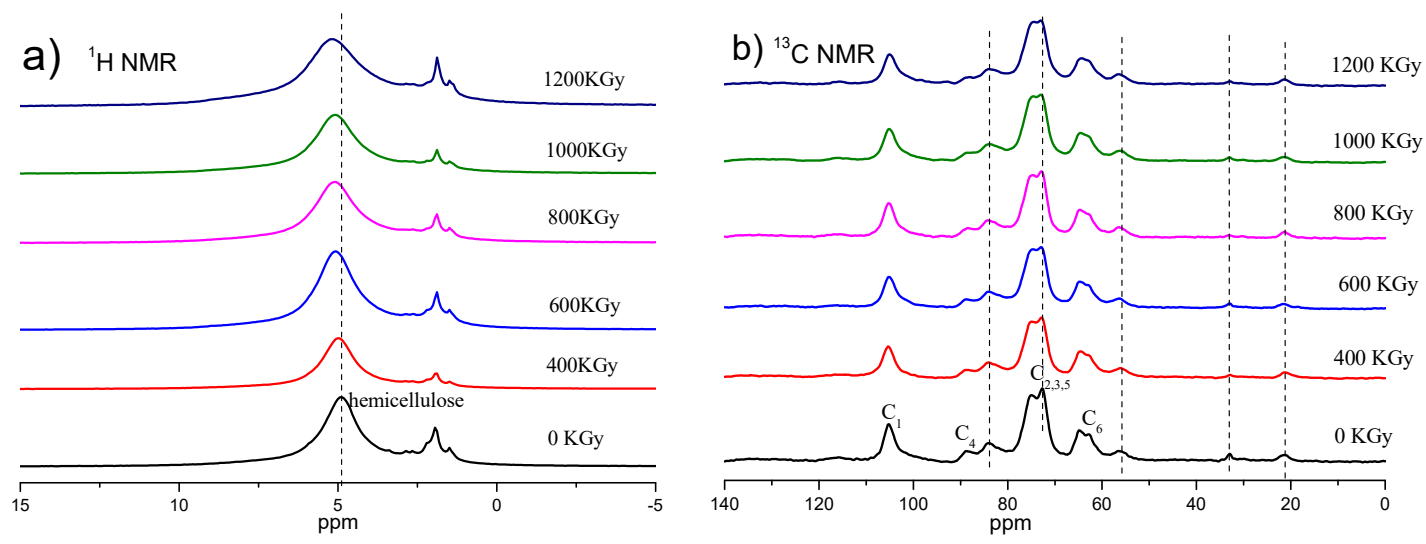

Figure 5. ${ }^{1} \mathrm{H}$ NMR (a) and ${ }^{13} \mathrm{C}$ NMR (b) profiles of Miscanthus irradiated with different doses.

\subsubsection{SEM Analysis}

The morphology of Miscanthus biomass after irradiation treatment was investigated by SEM, and the images are presented in Figure 6. The morphology of untreated Miscanthus (0 kGy) showed a smoothly compacted and ordered surface. After irradiation treatment, the surface morphology of 
samples displayed many small fragments, and the structure was rough and irregular. The degree of structural damage grew stronger with the increase in absorbed doses up to $1200 \mathrm{kGy}$. The phenomenon shows that irradiation treatment can effectively destroy the tight structure of the Miscanthus biomass, which was confirmed by many researchers in literature $[18,28,29]$. The morphology change of cellulose by irradiation treatment will improve the accessibility of cellulase to biomass, leading to high enzymatic digestibility $[14,30]$.
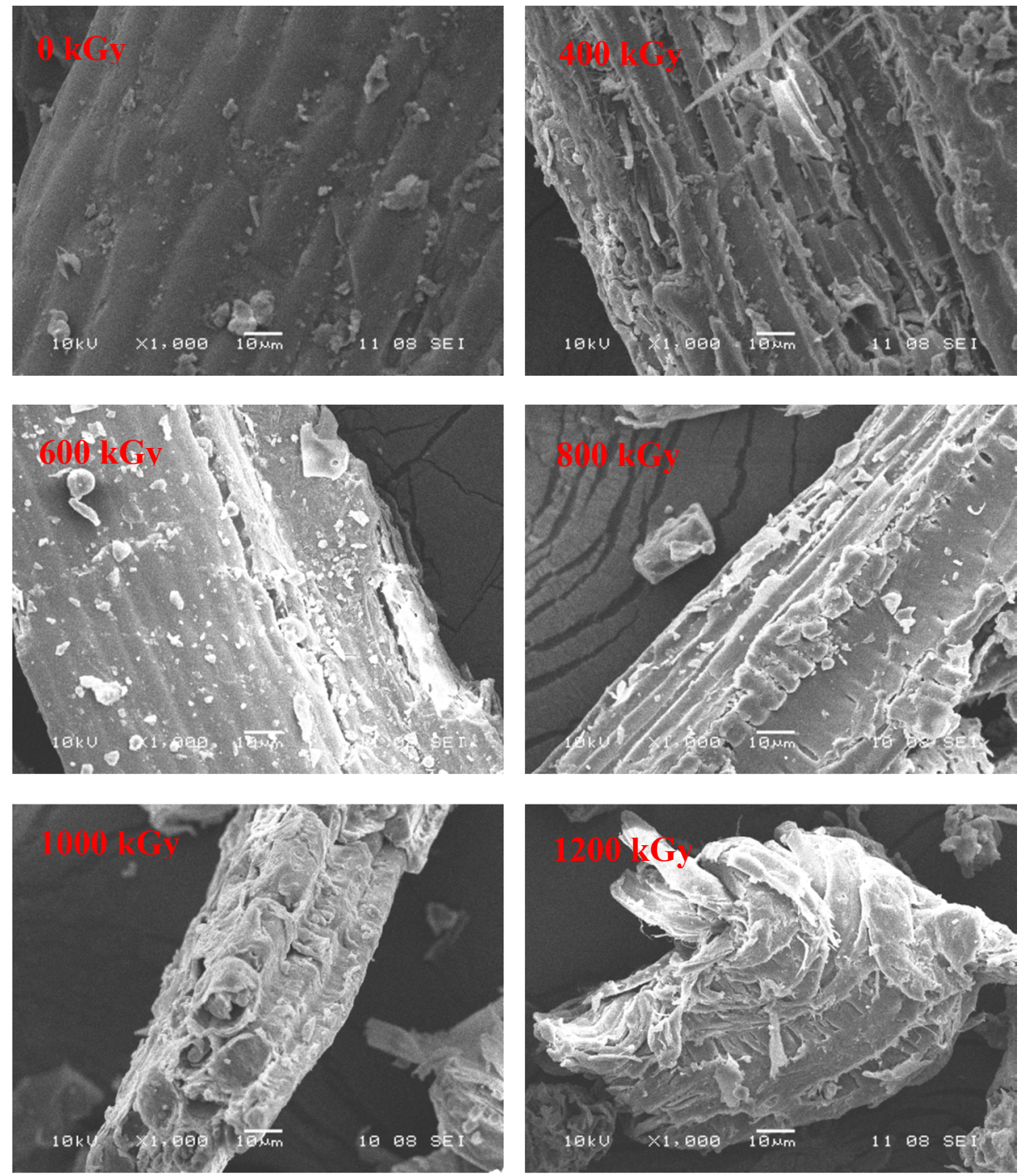

Figure 6. SEM photographs of untreated and irradiation-pretreated Miscanthus (1000×).

\subsubsection{AFM Analysis}

AFM images of untreated and irradiation treated Miscanthus biomass are shown in Figure 7. In the case of the untreated sample (0 kGy), the AFM image showed an intact and uniform surface, and the affinity of the AFM probe to the hydrophilic region is $46.53 \mathrm{~nm}$ (Figure 7a). For irradiation treated samples, their AFM images appeared non-uniform and there was a spherical surface in the amplitude phase, probably attributed to the exposure of cellulose (Figure $7 \mathrm{~b}-\mathrm{f}$ ). The affinity of the AFM probe to the hydrophilic regions increased up to $243.67 \mathrm{~nm}$. The light color of hydrophilic regions means a remarkable change in the phase image. A similar phenomenon was confirmed by other researchers in the literature [20,31]. Chundawat et al. [31] reported that the AFM probe adhered more keenly to hydrophilic areas, resulting in a greater change in the phase of the sample. 

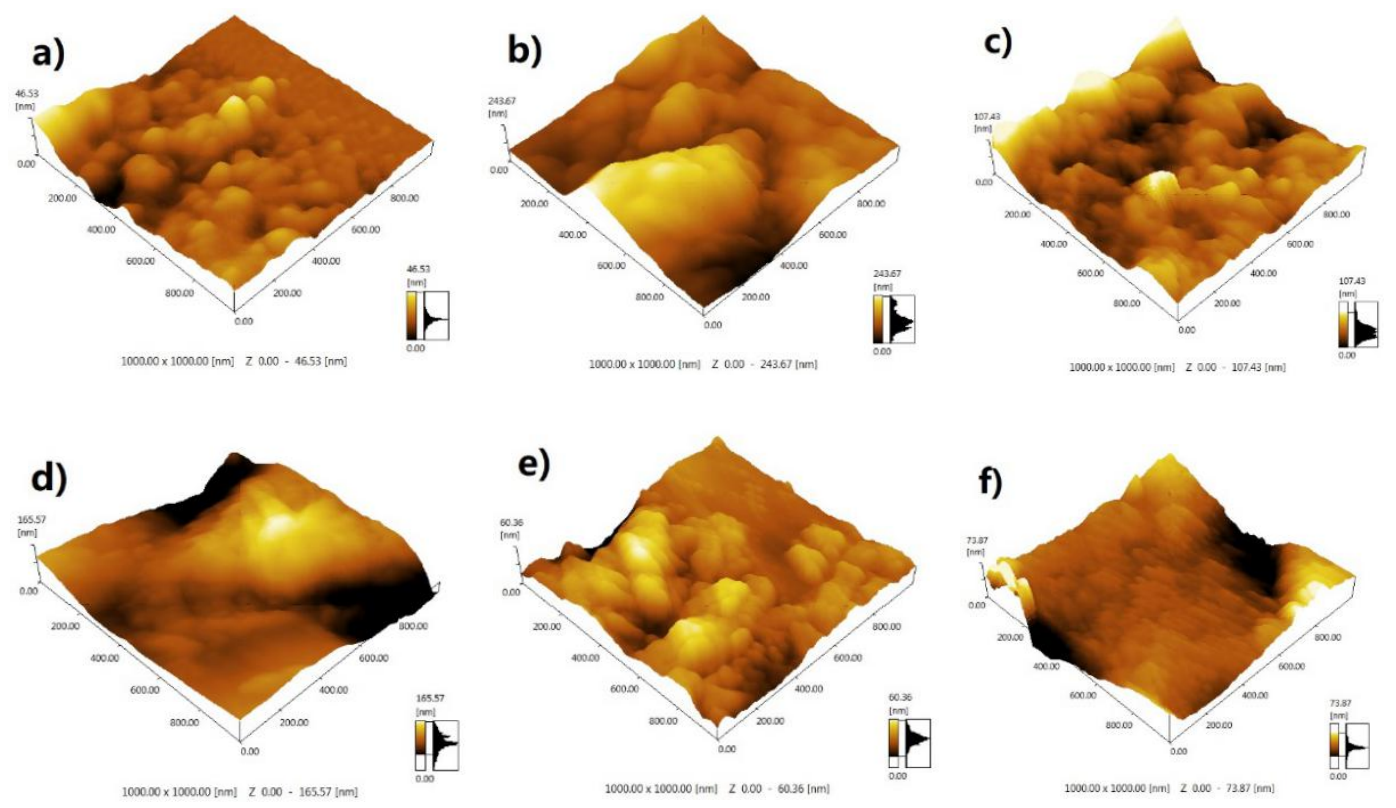

Figure 7. AFM images of untreated and irradiation treated Miscanthus biomass.

\section{Conclusions}

In summary, these findings demonstrate that $\gamma$-irradiation treatment can decrease crystalline cellulose, particle size, and DP while increasing the SSA of a biomass, resulting in the improvement in the cellulase accessibility to cellulose. Furthermore, irradiation treatment can substantially reduce structural and thermal stability by damaging the recalcitrant biomass structure. These structural changes in irradiated biomass will contribute to the further reduction of sugar release. The findings in this work provide an insight into the degradation mechanism of biomass by irradiation treatment, which is helpful for biomass biorefinery in the future. However, the practical application of irradiation treatment should be still discussed for its economic feasibility, which is under consideration in our laboratory.

Author Contributions: Conceptualization, X.-J.S. and Q.-M.L.; Methodology, C.-Y.Z., W.-J.L. and F.W.; Formal analysis, Y.L. and K.-Q.W.; Writing and checking draft manuscript, Q.-M.L., X.-J.S. and Y.L.; Visualization, Q.-M.L.; Funding acquisition, X.-J.S. All authors have read and agreed to the published version of the manuscript.

Funding: This work was supported by a special project for the construction of innovative provinces in Hunan Province of China (2019NK2031-2, 2019NK2031-3). This work was also funded by Hubei University of Science and Technology (2019-20KZ05).

Conflicts of Interest: The authors declare no conflict of interest.

\section{References}

1. Wang, Y.; Huang, J.; Li, Y.; Xiong, K.; Wang, Y.; Li, F.; Liu, M.; Wu, Z.; Tu, Y.; Peng, L. Ammonium Oxalate-Extractable Uronic Acids Positively Affect Biomass Enzymatic Digestibility by Reducing Lignocellulose Crystallinity in Miscanthus. Bioresour. Technol. 2015, 196, 391-398. [CrossRef]

2. Morandi, F.; Perrin, A.; Østergård, H. Miscanthus as Energy Crop: Environmental Assessment of a Miscanthus Biomass Production Case Study in France. J. Clean. Prod. 2016, 137, 313-321. [CrossRef]

3. Adams, J.M.M.; Winters, A.L.; Hodgson, E.M.; Gallagher, J.A. What Cell Wall Components are the Best Indicators for Miscanthus Digestibility and Conversion to Ethanol Following Variable Pretreatments. Biotechnol. Biofuels 2018, 11, 67-80. [CrossRef] [PubMed]

4. Xu, N.; Zhang, W.; Ren, S.; Liu, F.; Zhao, C.; Liao, H.; Xu, Z.; Huang, J.; Li, Q.; Tu, Y.; et al. Hemicelluloses negatively affect lignocellulose crystallinity for high biomass digestibility under $\mathrm{NaOH}$ and $\mathrm{H}_{2} \mathrm{SO}_{4}$ pretreatments in Miscanthus. Biotechnol. Biofuels 2012, 5, 58-69. [CrossRef] [PubMed] 
5. Van der Weijde, T.; Kamei, C.L.A.; Severing, E.I.; Torres, A.F.; Gomez, L.D.; Dolstra, O.; Maliepaard, C.A.; McQueen-Mason, S.J.; Visser, R.G.F.; Trindade, L.M. Genetic Complexity of Miscanthus Cell Wall Composition and Biomass Quality for Biofuels. BMC Genom. 2017, 18, 406-421. [CrossRef]

6. Cianchetta, S.; Bregoli, L.; Galletti, S. Microplate-Based Evaluation of the Sugar Yield from Giant Reed, Giant Miscanthus and Switchgrass after Mild Chemical Pre-Treatments and Hydrolysis with Tailored Trichoderma Enzymatic Blends. Appl. Biochem. Biotechnol. 2017, 183, 876-892. [CrossRef]

7. Alvira, P.; Tomas-Pejo, E.; Ballesteros, M.; Negro, M.J. Pretreatment Technologies for an Efficient Bioethanol Production Process Based on Enzymatic Hydrolysis: A Review. Bioresour. Technol. 2010, 101, 4851-4861. [CrossRef]

8. Zhang, X.; Yuan, Q.; Cheng, G. Deconstruction of Corncob by Steam Explosion Pretreatment: Correlations between Sugar Conversion and Recalcitrant Structures. Carbohydr. Polym. 2017, 156, 351-356. [CrossRef]

9. Zhang, T.; Wyman, C.E.; Jakob, K.; Yang, B. Rapid Selection and Identification of Miscanthus Genotypes with Enhanced Glucan and Xylan Yields from Hydrothermal Pretreatment Followed by Enzymatic Hydrolysis. Biotechnol. Biofuels 2012, 5, 56-69. [CrossRef]

10. Li, W.; Wang, W.; Xu, P.; Xu, P.; Zhao, X.; Wang, Y. Pretreatment of Miscanthus stalk with organic alkali guanidine and amino-guanidine. Bioresour. Technol. 2015, 179, 606-610. [CrossRef]

11. Li, M.; Si, S.; Hao, B.; Zha, Y.; Wan, C.; Hong, S.; Kang, Y.; Jia, J.; Zhang, J.; Li, M.; et al. Mild Alkali-Pretreatment Effectively Extracts Guaiacyl-Rich Lignin for High Lignocellulose Digestibility Coupled with Largely Diminishing Yeast Fermentation Inhibitors in Miscanthus. Bioresour. Technol. 2014, 169, 447-454. [CrossRef]

12. Vasco Correa, J.; Ge, X.; Li, Y. Fungal Pretreatment of Non-Sterile Miscanthus for Enhanced Enzymatic Hydrolysis. Bioresour. Technol. 2016, 203, 118-123. [CrossRef]

13. Tissot, C.; Grdanovska, S.; Barkatt, A.; Silverman, J.; Al-Sheikhly, M. On the mechanisms of the radiation-induced degradation of cellulosic substances. Rad. Phys. Chem. 2013, 84, 185-190. [CrossRef]

14. Liu, Y.; Zhou, H.; Wang, S.; Wang, K.; Su, X. Comparison of Gamma-Irradiation with other Pretreatments Followed with Simultaneous Saccharification and Fermentation on Bioconversion of Microcrystalline Cellulose for Bioethanol Production. Bioresour. Technol. 2015, 182, 289-295. [CrossRef] [PubMed]

15. Chen, J.; Wang, L.; Su, X.; Wang, K.; Wu, X.; Chen, L.; Xiong, X.; Zhou, H.; Liu, Y. Structure, Morphology, Thermostability and Irradiation Mediated Degradation Fractions of Hemicellulose Treated with $\gamma$-Irradiation. Waste Biomass Valorization 2016, 7, 1415-1425. [CrossRef]

16. Liu, Y.; Chen, J.; Wu, X.; Wang, K.; Su, X.; Chen, L.; Zhou, H.; Xiong, X. Insights into the effects of $\gamma$-irradiation on the microstructure, thermal stability and irradiation-derived degradation components of microcrystalline cellulose (MCC). RSC Adv. 2015, 5, 34353-34363. [CrossRef]

17. Su, X.; Hu, Q.; Wang, K.; Li, Q.; Cai, L.; Hu, T.; Jiang, Y.; Xiong, X. Enzymatic Hydrolysis and Structural Characterization of Miscanthus Straw Exposed to ${ }^{60} \mathrm{Co} \gamma$ - Ray Irradiation Pretreatment. J. Biobased Mater. Bioenergy 2015, 9, 55-61. [CrossRef]

18. Li, Q.; Li, X.; Jiang, Y.; Xiong, X.; Hu, Q.; Tan, X.; Wang, K.; Su, X. Analysis of degradation products and structural characterization of giant reed and Chinese silvergrass pretreated by $60 \mathrm{Co}-\gamma$ irradiation. Ind. Crop. Prod. 2016, 83, 307-315. [CrossRef]

19. Zhang, C.; Su, X.; Xiong, X.; Hu, Q.; Amartey, S.; Tan, X.T.; Qin, W. ${ }^{60}$ Co- $\gamma$ Radiation-Induced Changes in the Physical and Chemical Properties of Rapeseed Straw. Biomass Bioenergy 2016, 85, 207-214. [CrossRef]

20. Chandel, A.K.; Antunes, F.F.A.; Anjos, V.; Bell, M.J.V.; Rodrigues, L.N.; Singh, O.V.; Rosa, C.A.; Pagnocca, F.C.; Silva, S.S.D. Ultra-Structural Mapping of Sugarcane Bagasse after Oxalic Acid Fiber Expansion (OAFEX) and Ethanol Production by Candida Shehatae and Saccharomyces Cerevisiae. Biotechnol. Biofuels 2013, 6, 4. [CrossRef]

21. Yang, C.; Shen, Z.; Yu, G.; Wang, J. Effect and Aftereffect of $\gamma$ Radiation Pretreatment on Enzymatic Hydrolysis of Wheat Straw. Bioresour. Technol. 2008, 99, 6240-6245. [CrossRef] [PubMed]

22. Beardmore, D.H.; Fan, L.T.; Lee, Y.-H. Gamma-Ray Irradiation as a Pretreatment for the Enzymatic Hydrolysis of Cellulose. Biotechnol. Lett. 1980, 2, 435-438. [CrossRef]

23. Takács, E.; Wojnárovits, L.; Borsa, J.; Földváry, C.; Zöld, O. Effect of $\gamma$-Irradiation on Cotton-Cellulose. Radiat. Phys. Chem. 1999, 55, 663-666. [CrossRef]

24. Jiang, W.; Chang, S.; Qu, Y.; Zhang, Z.; Xu, J. Changes on structural properties of biomass pretreated by combined deacetylation with liquid hot water and its effect on enzymatic hydrolysis. Bioresour. Technol. 2016, 220, 448-456. [CrossRef] 
25. Zhang, J.; Feng, L.; Wang, D.; Zhang, R.; Liu, G.; Cheng, G. Thermogravimetric analysis of lignocellulosic biomass with ionic liquid pretreatment. Bioresour. Technol. 2014, 153, 379-382. [CrossRef]

26. Huang, C.; Lin, W.; Lai, C.; Li, X.; Jin, Y.; Yong, Q. Coupling the post-extraction process to remove residual lignin and alter the recalcitrant structures for improving the enzymatic digestibility of acid-pretreated bamboo residues. Bioresour. Technol. 2019, 285, 121355. [CrossRef]

27. Sun, J.; Xu, L.; Ge, M.; Zhai, M. Radiation degradation of microcrystalline cellulose in solid status. J. Appl. Polym. Sci. 2013, 127, 1630-1636. [CrossRef]

28. Hong, S.H.; Lee, J.T.; Lee, S.; Wi, S.G.; Cho, E.J.; Singh, S.; Lee, S.S.; Chung, B.Y. Improved enzymatic hydrolysis of wheat straw by combined use of gamma ray and dilute acid for bioethanol production. Radiat. Phys. Chem. 2014, 94, 231-235. [CrossRef]

29. Wang, K.Q.; Xiong, X.Y.; Chen, J.P.; Chen, L.; Su, X.J.; Liu, Y. Comparison of gamma irradiation and steam explosion pretreatment for ethanol production from agricultural residues. Biomass Bioenergy 2012, 46, 301-308. [CrossRef]

30. Li, C.; Liu, G.J.; Nges, I.A.; Liu, J. Enhanced biomethane production from Miscanthus lutarioriparius using steam explosion pretreatment. Fuel 2016, 179, 267-273. [CrossRef]

31. Chundawat, S.P.S.; Donohoe, B.S.; Sousa, L.D.C.; Elder, T.; Agarwal, U.P.; Lu, F.; Ralph, J.; Himmel, M.E.; Balan, V.; Dale, B.E. Multi-Scale Visualization and Characterization of Lignocellulosic Plant Cell Wall Deconstruction during Thermochemical Pretreatment. Energy Environ. Sci. 2011, 4, 973-984. [CrossRef]

(C) 2020 by the authors. Licensee MDPI, Basel, Switzerland. This article is an open access article distributed under the terms and conditions of the Creative Commons Attribution (CC BY) license (http://creativecommons.org/licenses/by/4.0/). 